\title{
Um estudo de follow up em psicoterapia psicanalítica de casais ${ }^{1}$
}

\author{
Maria Galrão Rios ${ }^{2}$ \\ Isabel Cristina Gomes \\ Universidade de São Paulo, São Paulo-SP, Brasil
}

\begin{abstract}
Resumo: Por 11 anos desenvolvemos uma pesquisa envolvendo uma proposta interventiva com famílias que buscam atendimento em um serviço-escola, com demanda localizada na criança. Por meio da psicoterapia psicanalítica com o casal procuramos atingir a remissão dos sintomas do(s) filho(s). O objetivo deste estudo é refletir sobre a manutenção das mudanças psíquicas ocorridas nesse tipo de clínica, que abrange a esfera conjugal e familiar, ao longo do tempo. Com base na metodologia de estudo de caso e no referencial psicanalítico, foram analisados dois casos clínicos enfatizando-se as sessões de follow up: dois casais que estiveram em processo terapêutico, respectivamente, por três anos e por dois anos e meio, sendo realizadas duas sessões de acompanhamento após o término da terapia. Esse tipo de intervenção mostrou-se efetiva para a elucidação de conflitos conjugais latentes e como promovedora de um ambiente saudável e favorecedor do desenvolvimento emocional da criança.
\end{abstract}

Palavras-chave: entrevista, psicoterapia psicanalítica, terapia de casais.

\section{A follow up study concerning psychoanalytical psychotherapy of couples}

\begin{abstract}
For eleven years we have been conducting a research that consists in a proposal of intervention with families that look for therapy for a child. Through the psychoanalytical psychotherapy of couples, we try to release the child's symptoms. The aim of this article is to reflect about the maintenance over time of the psychic changes obtained in this clinical practice, which evolves conjugal and familiar levels. Making use of the case study methodology and the psychoanalytic theory, two clinical cases were analyzed, with emphasis in follow up sessions: two couples that had been in therapy for 3 years and 2,5 years, and each couple has participated in two follow up interviews after the end of the therapy. This intervention showed up to be effective on the elucidation of latent conjugal conflicts and also as a promoter of a healthy and supportive environment in the emotional development of the child.
\end{abstract}

Keywords: interview, psychoanalytic psychotherapy, couples' therapy.

\section{Un estudio del follow up en psicoterapia psicoanalítica de parejas}

Resumen: Hace once años hemos desarrollado una investigación que consiste en una propuesta de intervención en familias que buscan atención con una demanda localizada en los niños. Por medio de la psicoterapia psicoanalítica con la pareja, intentamos alcanzar la remisión de los síntomas de lo(s) hijo(s). El objetivo de este artículo es reflexionar sobre la manutención de los cambios psíquicos ocurridos en ese tipo de clínica, que abarca la esfera conyugal y familiar, a lo largo del tiempo. A partir de la metodología del estudio de caso y del referencial psicoanalítico, dos casos clínicos fueron analizados, enfatizándose las sesiones de "follow up": dos parejas asistidas en psicoterapia, por 3 y 2,5 años, con los cuales se realizaron dos sesiones de acompañamiento después del término de la psicoterapia. Ese tipo de intervención fue efectivo en la detección de los conflictos conyugales latentes, proporcionando un ambiente favorecedor del desarrollo emocional del niño.

Palabras clave: entrevista, psicoterapia psicoanalítica, terapia de parejas

Há 11 anos estamos desenvolvendo um projeto de pesquisa envolvendo uma proposta interventiva com casais e/ou famílias que buscam atendimento em um serviço-escola de uma instituição acadêmica, com uma demanda localizada na criança (Gomes, 1998, 2006, 2007). Foram atendidos mais de 70 casos, nos quais se pôde comprovar o marcante efeito que a psicoterapia psicanalítica do casal de pais, ou de toda a família, exerce na remissão dos sintomas da criança. Tal projeto apóia-se em três bases: a prestação de serviço à comunidade, a formação

\footnotetext{
'Este texto foi revisado seguindo Acordo Ortográfico da Língua Portuguesa (1990), em vigor a partir de $1^{\circ}$ de janeiro de 2009.

${ }^{2}$ Endereço para correspondência:

Isabel Cristina Gomes. Universidade de São Paulo, Instituto de Psicologia, Departamento de Psicologia Clínica. Av. Prof. Mello Moraes, 1721, Bloco F. Cidade Universitária. CEP 05.508-030. São Paulo-SP, Brasil. E-mail: isagomes@usp.br
}

clínica dos alunos de psicologia - os atendimentos são realizados por estagiários, que recebem supervisão - e a produção de conhecimento teórico sistematizado. A partir deste último vértice foi surgindo a necessidade de se verificar a efetividade desta intervenção ao longo do tempo, o que gerou um interesse em pesquisar se os resultados obtidos - "cura" do filho e reestruturação na dinâmica familiar e/ou conjugal - se mantinham após o término do processo terapêutico.

Para tanto, realizamos um estudo de follow up com dois casais, A e B, que estiveram em processo terapêutico por períodos de três anos e de dois anos e meio, respectivamente. Com cada casal, foram realizadas duas sessões de acompanhamento: com o casal A, aos sete e aos 16 meses após o término da terapia; com o casal B, aos sete e aos 19 meses.

Pretendemos, neste artigo refletir sobre a manutenção, ao longo do tempo, das mudanças psíquicas ocorridas nesse tipo 
de clínica específica com casais (Gomes, 2007), que abrange a esfera conjugal e familiar.

\section{Uma clínica específica com casais}

Partindo-se do princípio de que, muitas vezes, o sintoma do filho pode ser produzido pela dinâmica familiar, o que inclui aspectos do relacionamento conjugal do casal parental, consideramos que o atendimento dos pais pode ser efetivo e suficiente para o desaparecimento do(s) sintoma(s) na criança.

Inicialmente era realizada a avaliação da criança, considerada como "doente" pela família, e caso o diagnóstico comprovasse a hipótese de o sintoma ser decorrente da dinâmica conjugal, as entrevistas de devolução com os pais eram prolongadas com a finalidade de esclarecê-los e conscientizá-los para a "mudança de foco", do filho para eles, propondo-se, então, um atendimento psicoterápico, de orientação psicanalítica, ao casal parental. Após o término da psicoterapia com os pais era realizada uma reavaliação da criança, para a verificação da manutenção da remissão dos seus sintomas (Gomes, 2006).

Com o transcorrer da experiência clínica e de pesquisa com as famílias atendidas, e com o aprofundamento no entendimento das dinâmicas conjugais e possibilidades de mudanças nestas relações, optamos por dispensar a etapa de avaliação direta da criança, nos casos em que as queixas eram fluidas e o casal já mencionava algum conflito conjugal e/ou familiar na entrevista inicial. Passamos, então, a propor diretamente o atendimento ao casal. Tomamos como base teórica referenciais fundantes da própria psicoterapia de família e casal, que apontam a estreita relação entre conjugalidade e parentalidade.

Ackerman (1969), nos primórdios da terapia familiar, afirmava que, muitas vezes, a verdadeira natureza do conflito marital era negada, deslocada ou projetada em outros laços familiares, como a relação pai(s)-filho(s); confirmando nossos achados atuais. Eiguer (1998) denominou de terapia de pais uma outra abordagem com o casal, na interface com a parentalidade, quando a terapia familiar não é possível de ser realizada por limitações na criança.

De acordo com as fundamentações acima, estruturou-se uma clinica com casais cuja demanda centrava-se nos sintomas do(s) filho(s) como forma intermediária para se chegar aos conflitos conjugais, que, por sua vez, interferiam no estabelecimento de um ambiente familiar saudável. Os dois casos clínicos considerados neste artigo envolveram atendimentos realizados já na segunda etapa do projeto e nenhuma das crianças chegou a ser avaliada.

O processo terapêutico em questão envolve a consideração da natureza do vínculo conjugal e familiar, levando-se em conta os aspectos transgeracionais e a psicopatologia dos mesmos, de acordo com Kaes (2001) e Correa (2000, 2007); bem como os referenciais da terapia psicanalítica familiar e de casal, segundo Eiguer (1995) e Berenstein (2007). Aqui se vê a necessidade de uma complementação à visão do terapeuta, por meio da interface com os estudos psicossociais que discutem, principalmente, as mudanças na família e no casamento contemporâneos (Roudinesco, 2003; Féres-Carneiro, 2009).

Nessa prática clinica procura-se resgatar um espaço de conjugalidade para os pais, por vezes perdido ou nem constituído, fazendo com que ele se fortaleça ou sofra mudanças, no sentido de gerar um ambiente mais saudável para toda a família. Nos casos de patologias mais graves envolvendo o casal, busca-se estabelecer uma distinção entre as esferas do conjugal e parental, na tentativa de assegurar um mínimo equilíbrio à dinâmica familiar e lugares distintos nas relações pais/filhos (Gomes, 2007). Nos casos de crise envolvendo toda a família, como em situações de mortes, rupturas, também consideramos que um atendimento de casal ou familiar possa ser mais efetivo do que o de um dos membros do grupo individualmente, corroborando outros autores da terapia familiar e de casal (Ramos, 1992, 1999; Soifer, 1983).

O objetivo desta intervenção, portanto, fundamenta-se em dois aspectos essenciais: o entendimento e transformação da demanda, da criança para o casal, numa proposta que envolve suprimir o lugar de "doente" ocupado por ela, na família, trazendo à tona, com isso, os conflitos do casal, numa tentativa de "resgate do conjugal" (Gomes, 2006).

$\mathrm{O}$ atendimento aos casais, nesse tipo de clinica com demanda indireta, possui algumas dificuldades, e salientamos as que surgem especialmente da resistência do casal no momento de transformação da demanda - da criança para eles (Gomes, 2003). Apesar disso, nos casos em que um trabalho com os pais torna-se possível, resultados animadores têm sido obtidos, com a melhora das crianças e de todo o contexto familiar. Embora tais resultados possam ser comprovados ao final do período de terapia, estudos envolvendo o acompanhamento dos casos pós-término ou follow up ainda não haviam sido realizados no projeto de intervenção e de pesquisa.

\section{Os estudos de follow up em psicanálise e em terapia familiar e de casal}

Os estudos de follow up têm se mostrado uma estratégia útil na análise da efetividade de diversas formas de terapia em psicologia, incluindo as psicoterapias de base psicanalítica (Wallerstein, 2005). Ao se fazer uma pesquisa de dados nas bases internacionais PsychINFO e MedLine, utilizando-se como palavras-chave "psychoanalysis" e "follow up", obtém-se 131 ocorrências de artigos e capítulos de livros publicados a partir do ano 2000. Destas, 48 dizem respeito especificamente a pesquisas ou reflexões acerca da efetividade de formas de psicoterapia, avaliando-se a manutenção dos resultados ao longo do tempo, após o término da intervenção. São estudos realizados em diversos países europeus, especialmente na Alemanha e Inglaterra, e também nos Estados Unidos. Apenas um deles envolve um país sul-americano, Chile, e abarca uma comparação entre técnicas de psicanálise, psicoterapia dinâmica, cognitivocomportamental e suportiva no tratamento de pacientes (Perry, 
2004). Nenhum destes trabalhos diz respeito a terapias realizadas com casais ou famílias na abordagem psicanalítica.

Cabe aqui uma reflexão acerca da relação entre a psicanálise e a estratégia de follow up, empregada originalmente em estudos quantitativos, muitas vezes com um referencial positivista de construção de conhecimento, que se distancia dos pressupostos da psicanálise como ciência e técnica terapêutica. De acordo com Orfanos (2006), a psicanálise vem apresentando amplo desenvolvimento nos últimos 25 anos, tanto no âmbito da teoria, quanto da clínica e da pesquisa. Neste último, o autor destaca a realização de estudos de acompanhamento, que examinam os efeitos do tratamento que se dão de maneira duradora.

Wallerstein (1999) realizou um amplo estudo de follow up e psicanálise, no qual discute o emprego de tal estratégia e seus efeitos na relação analista e analisando, salientando interferências na elaboração do fim do tratamento. Contudo, desenvolve seu raciocínio a favor do uso de tal estratégia com exemplos de contatos pós-análise que Freud estabelecia com seus analisandos.

Em sua pesquisa, com entrevistas de acompanhamento sendo realizadas entre dois e três anos após o término do processo analítico, Wallerstein (1999) concluiu que o impacto de um estudo planejado de follow up no término e no efeito de terapias psicanalíticas, embora nem sempre livre de consequências, não se mostra prejudicial e pode ser de valorosa ajuda nos desígnios terapêuticos tanto de analistas quanto de analisandos.

Em psicanálise, diversos fatores devem ser levados em conta para se entender a trajetória dos ex-analisandos e a avaliação da manutenção ou não dos resultados obtidos em análise. Entre tais fatores encontram-se as condições externas de vida, assim como os sistemas de suporte desenvolvidos e o ambiente familiar (Wallerstein, 1999). Além disso, é relevante analisar em que condições se deu o término do tratamento, ou seja, se ele foi determinado tanto por analista quanto por analisando ou se foi um término "forçado" pelo analista. Destacam-se, ainda, como influenciadores no desenvolvimento pós-terapia, os aspectos que não foram completamente ou suficientemente analisados durante o processo analítico.

Szecsödy (1999) contribui para essa temática buscando entender o processo de encerramento e o contato após o término, enfatizando as resistências dos próprios analistas em acompanhar os efeitos das análises através das entrevistas de follow up. Pondera ainda que, para a sobrevivência da psicanálise, é essencial que se lide com a falta de pesquisas bem documentadas que provem o valor e a efetividade do tratamento psicanalítico. Para ele, os estudos de follow up não apenas proporcionam uma legitimação externa da psicanálise, como também representam um método frutífero para se estudar as mudanças no método psicanalítico.

Para Leuzinger-Bohleber, Stuhr, Ruger e Beutel (2003), a crescente pressão pública e científica para que a psicanálise prove sua efetividade como método psicoterapêutico a ser financiado por planos de saúde faz com que a mesma formule argumentos próprios de acordo com sua especificidade, aceitando o desafio para desenvolver seus próprios estudos de acompanhamento da efetividade terapêutica ao longo do tempo, dentro da lógica psicanalítica.

Estudos que se utilizam do procedimento de follow up tornaram-se frequentes na última década. DeMaat, Philipszoon, Schoevers, Dekker e DeJonghe (2007) realizaram pesquisa acerca dos custos e benefícios de terapias psicanalíticas de longa duração. Elaboraram uma revisão sistemática de estudos publicados entre 1970 e 2005, analisando aqueles que foram considerados mais rigorosos. Concluem, então, que a terapia psicanalítica de longa duração reduz substancialmente a utilização de serviços de saúde, mesmo após o término da terapia. Nos estudos focalizados, a média de tempo do follow up foi de 2,9 anos, período no qual os resultados se mantiveram.

A questão da definição do tempo após o término da terapia ou intervenção em que se dá a entrevista de follow up é controversa, sendo variável nos artigos pesquisados. Percebe-se que, nestas pesquisas que envolvem referencial psicanalítico, os menores tempos de intervalo antes da primeira entrevista de acompanhamento são de três meses (Bateman \& Fonagy, 2001) e seis meses (Ciano, Rocco, Angarano, Biasin, \& Balestrieri, 2002; Leithner, Maar, \& Maritsch, 2002). Há diversas pesquisas nas quais o intervalo mínimo é de um ano (Falkenstrom, Grant, Broberg, \& Sandell, 2007; Grande e cols., 2006; Leichsenring, Biskup, Kreische, \& Staats, 2005; Lundblad, 2003; Porcerelli, Dauphin, Ablon, Leitman, \& Bambery, 2007). Dentre aquelas que envolvem maior intervalo entre o término da intervenção e a análise de acompanhamento, tal intervalo pode se localizar entre os quatro e oito anos (Beutel \& Rasting, 2002; Beutel, Rasting, Stuhr, Ruger, \& Leuzinger-Bohleber, 2004; Garyfallos e cols., 2002; Keller, Westhoff, Dilg, Rohner, \& Studt, 2001, 2002), podendo até mesmo chegar a $15 / 20$ anos (Colarusso, 2000; Tucker, 2006).

Em relação à terapia de casais, o único artigo que consta nas bases de dados internacionais consultadas, incluindo os descritores follow up e terapia de casal, é de orientação comportamental (Yi, 2008).

Embora nestas bases de dados constem dois trabalhos que abordem follow up e family therapy, a partir do ano 2000, apenas um deles se refere a avaliações de formas de terapia que envolvam uma etapa pós-término. Trata-se do texto de Wallin e Kronvall (2002), que estuda a anorexia nervosa em adolescentes. Este estudo avalia a mudança na função familiar depois da terapia de família. O intervalo de follow up adotado é de dois anos.

No Brasil, ao se empreender uma busca por estudos de follow up na base de dados SciELO, 22 artigos são acessados, embora todos eles se localizem na área médica. Na base de dados Dedalus, da Universidade de São Paulo, são citadas 19 ocorrências. Dentre os que avaliam formas específicas de psicoterapia, ressaltamos os seguintes trabalhos: Gebara, Rosa, Simon e Yamamoto (2004) avaliam a eficácia terapêutica da interpretação teorizada na Psicoterapia Breve de Abordagem 
Psicanalítica, utilizando dados de follow up. Fora da área psicanalítica, encontram-se trabalhos como o de Oliveira (1999) e de Silva, Facco e Silvares (2004), com intervalos de follow up variando de seis meses a dois anos na primeira, e de sete meses na segunda.

As diferenças nos resultados de tantas pesquisas pode se dever a diversos fatores metodológicos, como enfatiza Wallerstein (1999). Entre tais fatores, destacam-se a variedade no número de sujeitos; a população clínica estudada, o que inclui a severidade dos sintomas apresentados e os diferentes contextos de vida; o grau de treinamento dos analistas; os instrumentos de avaliação, assim como a maneira pela qual tais instrumentos são avaliados.

\section{Método}

Neste estudo utilizou-se o estudo de caso, dentro de uma proposta de pesquisa qualitativa na área clínica. A escolha pelos casos clínicos, discrepantes entre si em vários aspectos, deu-se a partir da concepção de que em pesquisa qualitativa a seleção dos participantes deve ser proposital, com uma escolha deliberada de respondentes, baseada na experiência e em possibilidades reais do pesquisador (Turato, 2003).

\section{Participantes}

Foram escolhidos dois casos clínicos, atendidos por uma das autoras que era estagiária do referido projeto, enquanto aluna de graduação e bolsista de iniciação científica, sendo que os casais estavam cientes que passariam pelo follow up, desde o início do processo terapêutico.

\section{Considerações éticas}

Como os atendimentos foram realizados na clínica-escola, seguiram os padrões éticos definidos pela instituição, ou seja, todo cliente na triagem assina um termo de consentimento informado permitindo o uso de material para pesquisa. No estudo atual, os nomes de todos os participantes foram alterados.

\section{Procedimentos}

\section{Coleta de dados}

As sessões com os casais foram realizadas nas dependências de uma clinica-escola, com a presença de ambos os cônjuges. Quanto ao casal B, dado o momento em que se inicia a terapia e a singularidade da dinâmica conjugal e familiar, introduziu-se a presença de um bebê recém-nascido no setting. As sessões não eram gravadas e ocorriam sempre na mesma sala de atendimento e em horários previamente agendados. Nos dois exemplos, a terapeuta que acompanhou a terapia dos casais foi a mesma que realizou as sessões de follow up.
A coleta do material clínico a ser analisado foi feita a partir dos recortes do registro cursivo das sessões, efetuados logo após a realização das mesmas, pela própria terapeuta, incluindo o registro de impressões e sentimentos contratransferenciais emergentes na sessão. Todas as sessões foram supervisionadas individualmente e as anotações, referentes às supervisões, foram utilizadas para aprofundar as análises.

Concordamos com Pavanelli (2007) quando argumenta que a escrita de um caso, pelo terapeuta, pode ser considerada uma forma privilegiada de mediação e, mais que isso, trânsito entre teoria e prática, constituindo-se assim como uma importante ferramenta de trabalho do psicólogo clínico/psicanalista. A autora considera fundamental a possibilidade de se distanciar - e de também se aproximar - da experiência clínica para refletir sobre ela. As vinhetas apresentadas neste artigo correspondem às falas dos pacientes permeadas pelas lembranças da terapeuta.

O casal A, Leda e Ari, foi atendido em terapia psicanalítica de casais pelo período de três anos, de 2003-2006, com frequência semanal. A primeira sessão de acompanhamento deu-se após sete meses do término da intervenção; a segunda, após 19 meses. O casal B, Anita e Rui, foi atendido pelo período de dois anos e meio, de 2003-2005, semanalmente até o segundo ano, e depois a cada quinze dias, combinação realizada em comum acordo pela dupla, tendo como base o próprio desenvolvimento do processo psicoterápico. As sessões de acompanhamento deram-se aos sete e aos 16 meses após a finalização da terapia. Em ambos os processos não houve o uso de co-terapia.

Os critérios definidos para os intervalos de realização das entrevistas de follow up, tendo como base a revisão da literatura, giraram em torno de seis meses após o término da terapia, a primeira e a segunda após 18 meses. Pequenas alterações deveram-se à interferência da forma de funcionamento da instituição que seguia o calendário escolar, interrompendo suas atividades nos meses de julho e final de ano, emendas de feriados, greves.

Os casais foram contatados pela terapeuta, via telefone, após o tempo acima delimitado. As entrevistas de follow up foram realizadas de acordo com o setting anterior.

\section{Análise dos dados}

Para a análise dos dados empregou-se a atividade interpretativa sedimentada na literatura psicanalítica que permitiu fazer algumas deduções, tomando-se como referência os dados coletados a partir dos registros cursivos das sessões. Enfatizamos o fato de terem sido considerados como indicativos da manutenção das mudanças psíquicas obtidas em terapia: o relato dos membros do casal acerca das mudanças e/ou melhoras alcançadas por eles e a remissão do sintoma(s) do(s) filho(s); as reflexões por eles realizadas sobre o próprio processo psicoterápico enfocando a diferenciação estabelecida entre os espaços do conjugal e parental. Além disso fazem parte da 
análise as observações da terapeuta - maneira com que o casal se organizou na sala, suas interações verbais e não-verbais, posicionamentos assumidos na sessão - e os sentimentos contratransferenciais nela suscitados.

\section{Resultados e Discussão}

\section{Casal A}

Caracterização familiar: A família era composta pelo casal, Leda com 49 anos e Ari com 60 anos, e dois filhos - uma menina de sete e um rapaz de 26 anos. O filho mais velho estava terminando a faculdade no Paraná, frequentando esporadicamente o lar. Leda era muito dedicada à profissão de professora, fazendo vários cursos e às vezes ausentando-se de casa para executar consultorias em outras cidades. Ari trabalhava numa empresa e estava próximo da aposentadoria.

A queixa inicial trazida pelo casal dizia respeito à filha caçula, Lúcia, que apresentava comportamentos de roubos e mentiras. A menina possuía um bom desempenho escolar e era sociável. As sessões iniciais foram marcadas pelas queixas de Leda em relação ao marido e pela apatia e aparente desinteresse deste, em relação aos sintomas da filha e a tudo que a esposa dizia. Desde a segunda sessão não se detinham nos problemas da filha, mas sim no que esses problemas causavam neles, pondo em evidência os conflitos conjugais latentes. O clima familiar caracterizava-se por uma intensa irritação tanto na esposa quanto no marido, por brigas e discussões frequentes, sendo que Leda e a filha acabavam por formar um par, no qual Ari ficava - e se deixava ficar - de fora. O casal, do ponto de vista transferencial, configurou o espaço clínico também de forma pareada, ou seja, Leda estabelece com a terapeuta um par e Ari se coloca de fora, não desejando participar.

Retomando a história familiar, o casal namorava quando Leda engravida do primeiro filho e resolvem se casar. Aqui temos uma conjugalidade que se estabelece na interface da parentalidade. Isso se repete na segunda gravidez que também não fora planejada, ocorrendo quando Leda tinha 40 anos e era considerada totalmente infértil por médicos. Isto faz pensar que o crescimento do filho mais velho do casal, com 18 anos na época, fora sentido como tão insuportável que uma outra criança tivesse que vir ocupar o lugar que estava ficando livre, comprovando, assim, a fragilidade do vínculo conjugal, em um casal com uma identidade conjugal (Féres-Carneiro, 1998) enfraquecida, ou seja, desprovida de desejos e projetos comuns.

Um outro aspecto importante da dinâmica conjugal e familiar dizia respeito a como o casal lidava com a profissão e o sustento da família. Ambos trabalhavam, porém o envolvimento profissional da esposa parecia ser maior que o do marido e seu ganho também. Ela trabalhava exaustivamente, muitas vezes delegando tarefas domésticas e de cuidado com a filha para o esposo. Este, após insucessos profissionais, desemprego, buscava a aposentadoria, permanecendo mais em casa. Essa divisão de tarefas, típica da família contemporânea, gerava muitas discussões no casal trazendo à tona o antigo dilema da interferência dos modelos tradicionais nas famílias organizadas em relações mais democráticas.

O esclarecimento da demanda inicial permitiu que, ao longo do processo psicoterápico, fossem trabalhadas várias vertentes da dinâmica conjugal e familiar, tais como: a conjugalidade estabelecida na interface com a parentalidade e a necessidade da inserção de terceiros entre eles - filhos ou o excesso, de trabalho da esposa; ambivalência da esposa entre os papeis de mãe, esposa e profissional; divisão de tarefas domésticas e a interferência do modelo tradicional de família. E ainda, a menina, ao invés de "doente", passou a ser vista como uma denunciadora dos conflitos conjugais de seus pais, que reconheceram a necessidade de ajuda para eles.

Com o desenvolvimento da terapia ocorreu a remissão dos sintomas da criança e, gradualmente, o casal passou a apresentar novas formas de vinculação, construindo alguns projetos em comum e delimitando um espaço de reflexão e de tentativa de construção de uma relação a dois, tudo isso envolto por resistências que foram sendo vencidas. Embora os avanços fossem sentidos na terapia, era grande a dificuldade deles em transportá-los para a vida cotidiana - já que, no setting analítico, necessariamente, eles contavam com a ajuda de um terceiro envolvido - o terapeuta.

Como estratégia clínica, resolveu-se, depois de 30 meses de terapia, definir um prazo de mais seis meses para o término do atendimento, com o intuito de desafiar a dependência do casal, em só entrar em contato com os aspectos mais conflitivos do vínculo conjugal na presença da terapeuta. A técnica de se estabelecer um prazo limite dentro da prática psicanalítica, principalmente em contexto institucional, não é nova, caracterizando as psicoterapias psicanalíticas breves. Contudo, é Freud (1918/1975, 1937/1980) quem introduz o tema pontuando que a determinação de um tempo-limite para o encerramento de uma análise, só deve ocorrer em circunstâncias especiais, principalmente quando se observa uma estagnação do processo terapêutico. Essa paralisação pode ser causada por uma dependência exagerada do analisando pelo analista, que pode se intensificar quando pensamos no setting grupal.

Durante os últimos seis meses, percebeu-se um desenvolvimento da conjugalidade no casal, embora, ao final do processo, Leda se mostrasse ressentida pela finalização. De acordo com o casal, eles valorizaram muito o "olhar para eles ao invés da filha", como se este já fosse um grande passo, mas mostravam-se, especialmente a esposa, temerosos em relação ao futuro sem terapia.

$\mathrm{Na}$ primeira sessão de acompanhamento ou follow up, sete meses após o término dos atendimentos, o casal não havia concretizado a maioria dos projetos em comum, retomando em certa medida a forma de vinculação anterior. Leda continuava se apoiando no excesso de trabalho como defesa para se manter afastada do marido. Entretanto, não mais depositaram a dificuldade conjugal na filha, que apresentava um desenvolvimento satisfatório, sem queixas. Nas palavras de Leda: 
Essa coisa que vocês estão fazendo aqui, de chamar os pais ao invés da criança, eu acho que no nosso caso isso foi muito bem visto. A Lúcia está bem! É com a gente mesmo. Eu tinha muito medo de não conseguir conversar com ele, mas até que a gente está conseguindo. Não que eu não sinta falta (se referindo à terapia), mas a gente está conseguindo...

Apesar desta fala, a sessão foi, em sua maior parte, caracterizada pela irritação do casal, pelas cobranças de Leda, pela ausência de Ari. Parecia que a única mudança permanente se restringia à remissão total dos sintomas da menina, e que uma reestruturação da dinâmica conjugal estivesse além dos limites deste par.

Na segunda sessão de acompanhamento, contudo, tal hipótese foi desconstruída. O casal no início da sessão demonstrou certo distanciamento e irritação, mas acabou por mostrar que os avanços obtidos no final da terapia haviam, enfim, se consolidado. Falaram de projetos em comum, relataram uma convivência mais satisfatória, valorizando a existência de um espaço conjugal de cumplicidade, compartilhando mais tempo e atividades conjuntas. Leda pôde fazer escolhas não tão excludentes entre o trabalho e a casa. Ari se colocou efetivamente mais próximo da filha, dividindo a tarefa de educá-la sem distanciamento. Era nítido o reconhecimento de ambos sobre a importância de conseguirem se comunicar adequadamente e creditavam esse mérito à terapia: ("Na terapia, eu cheguei com o pé atrás. Mas fui me abrindo com o tempo, conversando mais, foi bom..." Ari) e ("É verdade. Naquela época (referindo-se ao inicio da terapia), eu estava no olho do tornado. As coisas estavam muito dificeis para mim. Mas agora já dá para conversar..." Leda)

Sentaram-se juntos, e chegaram a se abraçar na sessão, fato que nunca ocorrera anteriormente. Ari colocou suas opiniões com maior ênfase do que o habitual. A filha, assim como no follow up anterior, não tivera nenhuma recaída, e não havia queixas a respeito dela.

A interpretação feita pela terapeuta, na sessão, foi a de que, no primeiro encontro após o término, era como se eles estivessem ainda ressentidos com a maneira como se deu a finalização. Entretanto, depois que se viram de fato tendo que "caminhar com as próprias pernas" se permitiram usufruir de todos os ganhos da terapia. Descobrindo e valorizando o espaço do conjugal, o respeito às individualidades, melhor adequação nas funções de cada um na família e, prioritariamente, não utilizar a filha como forma intermediária de veiculação dos conflitos maritais.

\section{Casal B}

Caracterização familiar: A família era composta pelo casal, Anita, 27 anos e Rui, 35 anos, e três filhos, o mais velho com seis anos, o do meio falecido aos três anos e uma menina recém-nascida.
Diferentemente do caso anterior, o casal foi encaminhado à terapia de casal após o psicodiagnóstico do filho mais velho João, então com seis anos, realizado por outra terapeuta, pois haviam passado por uma situação de crise familiar: a morte de Carlos, o filho até então caçula, com três anos, acontecida um ano antes. No início dos atendimentos, Anita estava grávida, esperando uma menina, para quem haviam escolhido o nome de Karla.

Iniciada a terapia, houve uma pausa de 50 dias com o nascimento de Karla, e quando os atendimentos foram retomados o bebê passou a participar semanalmente das sessões com seus pais: tanto porque o casal não tinha com quem deixá-la, quanto pelo caráter preventivo que a presença dela poderia assumir no sentido de não ser colocada no lugar de um morto, como era indicativo da escolha de seu nome. Após dois anos de terapia, os atendimentos passaram a ter frequência quinzenal e, aos 36 meses, foram finalizados.

Reflexões acerca da condução deste caso clínico, da configuração do setting analítico na presença do bebê e dos referenciais teóricos adotados foram apresentadas em publicação anterior (Rios \& Gomes, 2008). Neste artigo, apresentaremos resumidamente o processo psicoterápico do casal, e, em seguida, as sessões de acompanhamento.

O casal tinha um funcionamento complementar (Puget \& Berenstein, 1993) rígido, em que Anita exercia o papel da fraca, inadequada, incompetente e até mesmo deficiente e, Rui, no papel de forte, era o que resolvia os problemas de todos ao seu redor. Com a crise familiar, sustentar tal dinâmica exigia muito dos cônjuges. Rui tinha dificuldade em verbalizar e entrar em contato com o sofrimento advindo da morte do filho. Apesar disso, ele deixava muito claro que concordava em fazer terapia para ajudar a esposa, que precisava melhorar e aprender a "se virar mais sozinha".

O espaço terapêutico ofereceu acolhimento para esta situação, sendo trabalhado, então, o tipo de vinculação do par. Estabeleceram um vínculo mais flexível, o que possibilitou o florescer de um ambiente saudável para o desenvolvimento emocional do filho e da nova menina. Rui se permitiu assumir algumas fraquezas e angústias, e Anita passou a tomar para si algumas responsabilidades que antes eram do marido: ajudar o filho com a lição de casa, estabelecer uma mediação entre a casa e a escola do menino, entre outros (Rios \& Gomes, 2008).

A terapia deste casal, em seu aspecto preventivo, permitiu que Karla fosse retirada do lugar em que estava sendo colocada pelos pais - o de substituta do irmão morto, Carlos. Com a permissão de circulação da experiência traumática de perda vivida pela família, deu-se a possibilidade de metabolização da tragédia, antes encarada como indizível. Após dois anos de terapia, Rui chegou a verbalizar que achava que Karla pudesse ser a reencarnação de Carlos, e a reação da menina - dirigir-se ao pai e vomitar - parece tê-la liberado deste papel.

$\mathrm{Na}$ primeira sessão de acompanhamento, sete meses após o término dos atendimentos, manteve-se a flexibilidade alcançada no vínculo do casal, em que a esposa assumia 
responsabilidades, sentindo-se capaz de acompanhar o desenvolvimento de seus filhos, e o marido se permitia entrar em contato com suas fraquezas e sofrimentos. Os dois filhos apresentavam um desenvolvimento satisfatório, e sem queixas. Rui, ao falar do processo de terapia, preferiu relatar todas as melhoras que sentira na esposa, sem se implicar muito:

Teve altos e baixos, (a terapia) mas principalmente a parte do finalzinho eu acho que foi muito boa. Ela mudou muito! Você sabe, que eu vim aqui por causa dela. Tá perfeito! Agora eu não preciso mais me preocupar com as coisas, ela que cuida. (Rui)

Anita, frente a esta colocação, não abaixou a cabeça e nem se calou, como ela fazia no início dos atendimentos, e comentou que o marido também estava melhor, e que ela não era a única que havia mudado. Karla, que esteve presente também nesta sessão, apresentou muita vivacidade, fez desenhos, e os entregou para a terapeuta antes de ir embora.

Na segunda sessão de acompanhamento, aos 19 meses após o término da terapia, Karla também estava lá. Alegre e falante, participou ativamente da sessão, brincando e fazendo comentários. De acordo com os pais, a saúde e o desenvolvimento da menina estavam ótimos, embora ela não gostasse muito de ir à escola - onde ela havia sido colocada há três meses.

Em relação ao filho mais velho, surgiram novas queixas. O menino, que teve episódios de convulsão, havia sido diagnosticado como portador de epilepsia. A preocupação do casal era de que a medicação estivesse deixando o garoto muito "sedado", o que justificaria seu baixo rendimento escolar.

Quanto à dinâmica conjugal, ambos enfatizaram nesta sessão que o relacionamento estava bom, e que os dois haviam conseguido manter os ganhos obtidos com a terapia: ("Foi muito bom pra gente. A gente cresceu. Hoje em dia, as pessoas não se aproveitam mais dela. Lembra como era?"); ("Eu sempre fui mais fechado, sempre falei isso, mais dificil") (Rui) e ("Isso é verdade, antes, se ele chegava em casa com dor, nem queria falar nada, e ficava nervoso... E as pessoas falam que eu mudei foi muito! Agora eu que vou pagar as contas!") (Anita).

Pode-se dizer que este casal, ao final da terapia e nas sessões de acompanhamento, ainda mantinha um tipo de vínculo complementar (Puget \& Berenstein, 1993), em que o marido assume o papel de cuidador, e a esposa o de fragilidade. Por mais que a estrutura do vínculo não tenha sido alterada, considera-se que houve, e manteve-se, um aumento na flexibilidade com que se dá tal complementaridade, com uma maior abertura de Rui para entrar em contato com suas dores psíquicas, e com uma maior participação de Anita nas responsabilidades da casa, e, especialmente, por seu posicionamento perante o marido, a terapeuta, os filhos.

A grande "conquista" deste atendimento, dimensionado entre as esferas do conjugal e parental, foi ter propiciado além de uma maior flexibilização dos papéis assumidos por marido e mulher, a constatação de que a filha do casal segue um desenvolvimento saudável e criativo. Criatividade que, em uma visão winnicottiana, seria provavelmente inibida se ela tivesse que responder às expectativas inconscientes dos pais de que ela fosse uma reencarnação do irmão morto.

Respeitando-se a singularidade de cada caso e o percurso realizado na psicoterapia de cada um deles, percebeu-se que muitas das mudanças obtidas em terapia se mantiveram ao longo do tempo, confirmando os estudos de follow up na abordagem psicanalítica de Orfanos (2006) e Wallerstein (1999, 2005). No casal A, mantém-se a ausência de queixas em relação à filha, tanto aos sete quanto aos 16 meses pós-término, e a criação de um espaço de conjugalidade no par que foi, inclusive, sendo reforçado na medida em que os atendimentos foram finalizados. Chama a atenção neste caso a importância de se analisar uma sessão de follow up levando-se em consideração todo o contexto de atendimento e a forma como se deu o término do processo psicoterápico, nas complexas relações de transferência e contratransferência, como enfoca Wallerstein (1999).

Para o casal B, a manutenção de uma maior flexibilidade no vínculo conjugal ainda que preservando uma certa complementaridade no par e, especialmente, um desenvolvimento criativo e saudável da filha, são indicadores satisfatórios dos progressos obtidos e mantidos ao longo do tempo, pela terapia.

Nos dois casos, os sintomas dos filhos indicavam conflitos latentes na dinâmica conjugal e familiar. O espaço da terapia com os casais possibilitou a emersão desses conflitos, liberando as crianças para um desenvolvimento saudável.

Quanto ao papel do terapeuta, que se coloca como um facilitador para o surgimento do espaço conjugal desvinculado do parental, as sessões de follow up promovem um duplo reasseguramento, ou seja, para o clínico, como uma forma de avaliar sua capacidade profissional e para os pacientes, a percepção de um vir a ser que pôde ser implantado. Contudo, determinar um período de tempo para as mudanças psíquicas ocorrerem ou se solidificarem é sempre algo singular, o que leva a uma questão controversa o uso dessa técnica dentro da psicanálise, daí decorrendo a discrepância entre os tempos de intervalo utilizados nas pesquisas acima citadas, bem como o reduzido número de trabalhos que se utilizam de tal técnica, em psicanálise.

\section{Considerações finais}

Uma clínica psicanalítica com casais, cuja demanda é pontuada no(s) sintoma(s) do(s) filho(s), como forma de encobrir o surgimento de conflitos conjugais e familiares latentes sugere que o trabalho terapêutico priorize o casal, ajudando-o, prioritariamente, na discriminação dos espaços - conjugal e parental. Esse tipo de intervenção, tomando-se como exemplo os dois casos clínicos relatados acima, mostrou-se efetiva como promovedora de um ambiente saudável e favorecedor do desenvolvimento emocional da criança, com a possibilidade de manutenção da remissão dos sintomas e das mudanças psíquicas adquiridas, com o passar do tempo. 
Os estudos de follow up, que permitem avaliar continuamente a efetividade das estratégias de intervenção psicoterapêuticas em geral, ainda hoje não são muito utilizados em se tratando das psicoterapias psicanalíticas, principalmente as que envolvem a clinica com casais e famílias. Entretanto, é consenso geral na literatura específica que processos de longa duração necessitam comprovar resultados, dada as exigências dos serviços de saúde e outros tipos de institições que oferecem esses atendimentos. Em se tratando, especificamente, dos serviços-escola que além do binômio paciente/terapeuta comprometem-se com a formação do futuro profissional, isso se torna imperioso.

Pesquisar novos tipos de intervenção psicoterapêutica, com casais e/ou famílias, cujas mudanças ou resultados obtidos são mantidos ao longo do tempo e adquirem características preventivas, preenchem os anseios ou os sofrimentos humanos atuais e contribuem para o desenvolvimento dessa clínica específica.

\section{Referências}

Ackerman, N. W. (1969). Psicoterapia de la família neurótica. Buenos Aires: Paidós.

Bateman, A., \& Fonagy, P. (2001). Treatment of borderline personality disorder with psychoanalytically oriented partial hospitalization: An 18-month follow up. American Journal of Psychiatry, 158, 36-42.

Berenstein, I. (2007). Del ser al hace: Curso sobre vincularidad. Buenos Aires: Paidós.

Beutel, M., \& Rasting, M. (2002). Long-term treatments from the perspectives of the former patients. In M. Target \& M. Leuzinger-Bohleber (Eds.), Outcomes of psychoanalytic treatment: Perspectives for therapists and researchers (pp. 130-142). Philadelphia, PA: Whurr Publishers.

Beutel, M., Rasting, M., Stuhr, U., Ruger, B., \& LeuzingerBohleber, M. (2004). Assessing the impact of psychoanalyses and long-term psychoanalytic therapies on health care utilization and costs. Psychotherapy Research, 14, 146-160.

Ciano, R., Rocco, P. L., Angarano, A., Biasin, E., \& Balestrieri, M. (2002) . Group-analytic and psychoeducational therapies for binge-eating disorder: An exploratory study on efficacy and persistence of effects. Psychotherapy Research, 12, 231-239.

Colarusso, C. A. (2000). A child-analytic case report: A 17-year follow up. In B. J. Cohler, J. Bertram, \& J. Cohen (Eds.), The psychoanalytic study of lives over time: Clinical and research perspectives on children who return to treatment in adulthood (pp. 49-65). San Diego, CA: Academic Press.

Correa, O. B. R. (Org.). (2000). Os avatares da transmissão psíquica geracional. São Paulo: Escuta.

Correa, O. B. R. (Org). (2007). Grupo familiar e psicanálise: Ressonâncias clínicas. São Paulo: Vetor.

DeMaat, S., Philipszoon, F., Schoevers, R., Dekker, J., \& De Jongue, F. (2007). Costs and benefits of long-term psychoanalytic therapy: Changes in health care use and work impairment. Harvard Review of Psychiatry, 15, 289-300.
Eiguer, A. (1995). O parentesco fantasmático: Transferência e contratransferência em terapia familial psicanalítica (M. A. Chiarella, Trad.). São Paulo: Casa do Psicólogo.

Eiguer, A. (1998). Clinique psychanalytique du couple. Paris: Dunod.

Falkenstrom, F., Grant, J., Broberg, J., \& Sandell, R. (2007). Self-analysis and post-termination improvement after psychoanalysis and long-term psychotherapy. Journal of the American Psychoanalytical Association, 55, 629-674.

Féres-Carneiro, T. (1998). Casamento contemporâneo: O difícil convívio da individualidade com a conjugalidade. Psicologia: Reflexão e Crítica, 11, 379-394.

Féres-Carneiro, T.(Org.).(2009). Casalefamília: Permanências e rupturas. São Paulo: Casa do Psicólogo.

Freud, S. (1980). História de uma neurose infantil (M. A. M. Rego, Trad.). In J. Salomão (Org.), Edição standard brasileira das obras psicológicas completas de Sigmund Freud (Vol. 17, pp. 13-153). Rio de Janeiro: Imago. (Original publicado em 1918)

Freud, S. (1975). Análise terminável e interminável (M. A. M. Rego, Trad.). In J. Salomão (Org.), Edição standard brasileira das obras psicológicas completas de Sigmund Freud (Vol. 23, pp. 239-288). Rio de Janeiro: Imago. (Originalmente publicado em 1937)

Garyfallos, G., Adamopoulus, A., Karastergious, A., Voikli, M., Zlatanos, D., \& Tsifida, S. (2002). Evaluation of cognitiveanalytic therapy (CAT) outcome: A 4-8 year follow up. European Journal of Psychiatry, 16, 197-209.

Gebara, A. C., Rosa, J. T., Simon, R., \& Yamamoto, K. (2004). Eficácia terapêutica da interpretação teorizada na psicoterapia breve. Psic: Revista de Psicologia Vetor, 5(1), 6-15.

Gomes, I. C. (1998). O sintoma da criança e a dinâmica do casal. São Paulo: Escuta.

Gomes, I. C. (2003). Alcances e limites da psicoterapia psicanalítica com casais e famílias. In T. FeresCarneiro (Org.), Família e casal: Arranjos e demandas contemporâneas (pp. 215-224). Rio de Janeiro São Paulo: PUC-Rio/ Loyolla.

Gomes, I. C. (2006) Uma clínica especifica com casais: Contribuições teóricas e técnicas. Tese de livre-docência não publicada, Instituto de Psicologia, Universidade de São Paulo, São Paulo.

Gomes, I. C. (2007). Uma clínica especifica com casais: Considerações teóricas e clínicas. São Paulo: Escuta/ FAPESP.

Grande, T., Dilg, R., Jakobsen, T., Keller, W., Krawietz, B., Langer, M., Oberbracht, C., Stehle, S., Stennes, M., \& Rudolf, G. (2006). Differential effects of two forms of psychoanalytic therapy: Results of the Heidelberg-Berlin study. Psychotherapy Research, 16, 470-485.

Kaës, R. (Org.). (2001). Transmissão da vida psíquica entre gerações (C. Berliner, Trad.). São Paulo: Casa do Psicólogo. 
Rios, M. G., \& Gomes, I. C. (2011). Follow up: psicanálise de casais.

Keller, W., Westhoff, G., Dilg, R., Rohner, R., \& Studt, H. (2001). Efficacy and utilization of health insurance in patients undergoing long-term psychoanalysis: Results of an empiric follow up study on the efficacy of (Jungian) psychoanalysis and psychotherapy. Analytische Psychologie, 32, 202-229.

Keller, W., Westhoff, G., Dilg, R., Rohner, R., \& Studt, H. (2002). Efficacy and cost effectiveness aspects of outpatient (Jungian) psychoanalysis and psychotherapy-a catamnestic study. In M. Target \& M. Leuzinger-Bohleber (Eds.), Outcomes of psychoanalytic treatment: Perspectives for therapists and researchers (pp. 186-197). Philadelphia, PA: Whurr Publishers.

Leichsenring, F., Biskup, J., Kreischer, R., \& Staats, H. (2005). The Gottingen study of psychoanalytic therapy: First results. International Journal of Psychoanalysis, 86, 433-455.

Leithner, K., Maar, A., \& Maritsch, F. (2002). Experiences with a psychological help service for women following a prenatal diagnosis: Results of a follow up study. Journal of Psychosomatic Obstetrics and Gynaecology, 23, 183-192.

Leuzinger-Bohleber, M., Stuhr, U., Ruger, B., \& Beutel, M. (2003). How to study the quality of psychoanalytic treatments and their long-term effects on patients' wellbeing: A representative, multi-perspective follow up study. International Journal of Psychoanalysis, 84, 263-290.

Lundblad, S. (2003). Depressed women in psychotherapy: The nature and persistence of change. International Journal of Psychotherapy, 8, 53-63.

Oliveira, D. S. (1999). O uso do aparelho de alarme no tratamento comportamental da enurese infantil noturna. Dissertação de mestrado não publicada, Instituto de Psicologia, Universidade de São Paulo.

Orfanos, S. D. (2006). On such a full sea: Advances in Psychoanalytic Psychology. Journal of the New York State Psychological Association, 3(4), 2-8.

Pavanelli, C. L. (2007). A teoria como objeto interno do analista e seus destinos na clínica: Luto e melancolia como metáfora. Dissertação de mestrado não publicada, Instituto de Psicologia, Universidade de São Paulo.

Perry, J. C. (2004). Un estudio controlado alazar en psicoanalisis y otras psicoterapias: Consideraciones y diseño. Revista Chilena de Psicoanálisis, 21(1), 35-44.

Porcerelli, J. H., Dauphin, V. B., Ablon, J. S., Leitman, S., \& Bambery, M. (2007). Psychoanalysis with avoidant personality disorder:Asystematic case study. Psychotherapy: Theory, Research, Practice, Training, 44, 1-13.

Puget, J., \& Berenstein, I. (1993). Psicanálise do casal (F. F. Settineri, Trad.). Porto Alegre: Artes Médicas.

Ramos, M. (Org). (1992). Terapia de casal e família. São Paulo: Brasiliense.

Ramos, M. (1999). Casal e família como paciente (2a ed.). São Paulo: Escuta.
Rios, M. G., \& Gomes, I. C. (2008). A inclusão de um bebê em sessões de psicoterapia psicanalítica de casal com seus pais: Relato de um caso. In I. C. Gomes (Org.), Família: Diagnóstico e abordagens terapêuticas. Rio de Janeiro: Guanabara-Koogan.

Roudinesco, E. (2003). A família em desordem. (A. Telles, Trad.). Rio de Janeiro: Jorge Zahar.

Silva, R. A. P., Facco, M. A., \& Silvares, E. F. M. (2004). Enurese noturna infantil. Tratamento comportamental com aparelho de alarme e seguimento como controle de recaída: Estudo de caso. Jornal Brasileiro de Psiquiatria, 53, 113122.

Soifer, R. (1983). Psicodinamismos da família com crianças (E. F. Alves, Trad.). Petrópolis, RJ: Vozes.

Szecsödy, I. (1999). How can we end psychoanalysis - and still have a follow up for it? The Scandinavian Psychoanalytic Review, 22(1), 48-66.

Tucker, L. J. (2006). The Grandparent Syndrome: A case study. The Psychoanalytic Study of the Child, 61, 82-98.

Turato, E. R. (2003). Tratado da metodologia da pesquisa clínico-qualitativa: Construção teórica-epistemológica, discussão comparada e aplicação nas áreas da saúde e humanas. Petrópolis, RJ: Vozes.

Wallerstein, R. S. (1999). Psychoanalysis: Clinical and theoretical. Connecticut: International Universities Press.

Wallerstein, R. S. (2005). Outcome research. In G. O. Gabbard, E. S. Person, \& A. M. Cooper (Eds.), The American psychiatric publishing textbook of psychoanalysis (pp. 301315). Washington, DC: American Psychiatric Publishing.

Wallin, U., \& Kronvall, P. (2002). Anorexia nervosa in teenagers: Change in family function after family therapy, at 2-year follow up. Nordic Journal of Psychiatry, 56, 363369.

Yi, J. C. (2008). Ethnic minorities in couple therapy: A five-year follow up. Dissertation Abstracts International. Section-B. The Sciences and Engineering, 68(7), 48-53.

Maria Galrão Rios é doutoranda pelo Programa de Pós-graduação em Psicologia Clínica do Instituto de Psicologia da Universidade de São Paulo, bolsista CAPES.

Isabel Cristina Gomes é Professora Associada do Instituto de Psicologia da Universidade de São Paulo.

Recebido: 30/08/2009

$1^{a}$ revisão: 20/01/2010

$2^{a}$ revisão: 09/11/2010

Aceite final: 20/12/2010 